\title{
Electromagnetic Wave Absorption by Rice Hull Carbon
}

\author{
Mitsuhiro Kaneta*, Takeshi Takahashi**, Tomoyuki Kanaya*** and Hiroshi Iizuka**** \\ * Graduate School of Science and Engineering, \\ Yamagata University, 4-3-16 Jonan, Yonezawa 992-8510, Japan \\ Fax: +81-238-26-3212, e-mail: dws21711@dip.yz.yamagata-u.ac.jp \\ **Sanwa Yushi Co.Ltd., Tendo 994-0044, Japan \\ ***Miyasaka Polymer Co.Ltd., Yonezawa 992-0083,Japan \\ ****Faculty of Engineering, Yamagata University, 4-3-16 Jonan, Yonezawa 992-8510, Japan
}

We have carried out the project for the useful utilization of the remaining rice hull as an industrial carbon material. The rice hull carbon (RHC) powder is manufactured by carbonizing in a nitrogen gas atmosphere at high temperature, then crushing and sieving. The rice hull has a natural porous structure. The diameter of the unit cell is about $10 \mu \mathrm{m}$. The porous structure retained even after the carbonizing and crushing. The composite material comprised of the RHC and Ethylene Propy -lene Diene Methylene linkage rubbers is manufactured by molding and vulcanizing. In this study, the characteristic of electromagnetic wave absorption (reflectivity) was measured in frequency band between $50 \mathrm{MHz}$ and $8 \mathrm{GHz}$ for the composite material. The composite material possessed a high characteristic of electromagnetic wave absorption for $2 \mathrm{GHz}-8 \mathrm{GHz}$. The characteristics were further affected by the test piece thickness and theRHC powder content.

Key words: Rice-Hull, Porous carbon material, Rubber composite material, Electromagnetic wave absorption, Reflectivity.

\section{INTRODUCTION}

Rice is a staple food, and its amount is about 10 million tons per year in Japan. The rice hull is the by-product of the rice and the amount is about 2.6 million tons per year [1]. About 1.7million tons of the rice hull is reused as a fertilizer, a carbonizing chaff and a soil conditioner, etc. The rice hull contains about 80 mass $\%$ of the organic constituent and 20 mass $\%$ of the inorganic constituent. The main inorganic constituent is silica, whose amount is more than 95mass\% [2]. The authors have carried out the project for the useful utilization of the remaining rice hull as an industrial carbon material $[3,4]$.

The rice hull carbon (RHC) powder is manufactured by carbonizing the rice hull in a nitrogen gas atmosphere at high temperature, then crushing and sieving the carbonized particles. The RHC powder contains about 56 mass $\%$ of the carbon, about 32 mass $\%$ of the oxygen and about 9 mass $\%$ of the silicon. The RHC powder is expected to use as a functional filler for the plastics and rubbers, since it provides new functions for the composite material [5].

In this study, the characteristic of electro -magnetic wave absorption (reflectivity) was measured in frequency band between $50 \mathrm{MHz}$ and $8 \mathrm{GHz}$ for the composite material comprised of RHC/Ethylene Propylene Diene Methylene linkage (EPDM). More over, the influence of RHC powder contents and test piece thickness on the electromagnetic wave absorption was evaluated.

\section{EXPERIMENTAL PROCEDURE}

2.1 Manufacturing process

Fig.1 shows the manufacturing process of the RHC powder and the RHC/EPDM composite. At first, the rice hull was carbonized in nitrogen gas atmosphere at $900^{\circ} \mathrm{C}$ for 3 hours. The carbonized rice hull was then pulverized by a mill to obtain the RHC powder. The RHC powder was sieved by $106 \mu \mathrm{m}$ meshed filter to obtain the powder of $20 \mu \mathrm{m}$ median diameter. The composite material of the RHC powder and EPDM is manufactured by molding and vulcanizing.

Fig.2 shows the natural porous structure of the rice hull. The diameter of the unit cell is about $10 \mu \mathrm{m}$. Fig. 3 shows the macrostructure of the RHC powder. The porous structure retains even after the carbonizing and crushing.

\subsection{Test pieces}

The electromagnetic wave absorption characteristic was evaluated dividing the measuring bands into $50 \mathrm{MHz}$ $-3 \mathrm{GHz}$ and $2 \mathrm{GHz}-8 \mathrm{GHz}$.

Fig.4 (a) shows the test piece of $\mathrm{S}$ parameter method for $50 \mathrm{MHz}-3 \mathrm{GHz}$. The shape of the test piece is toroidal. Fig.4 (b) shows the test pieces of arch method for $2 \mathrm{GHz}-8 \mathrm{GHz}$. The geometry of the test piece is $300(\mathrm{w}) \times 300(\mathrm{~h}) \times \mathrm{t}($ thickness $)$. 


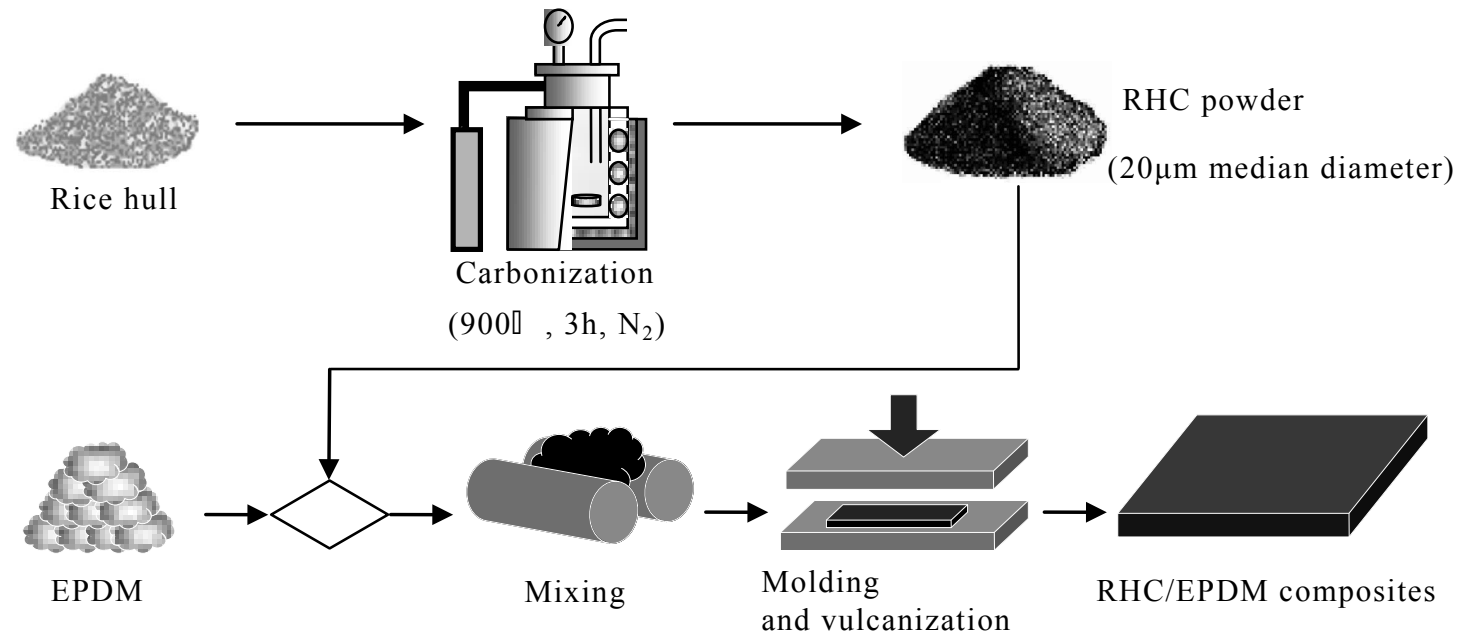

Fig. 1 Manufacturing process of RHC powder and rubber composite material.

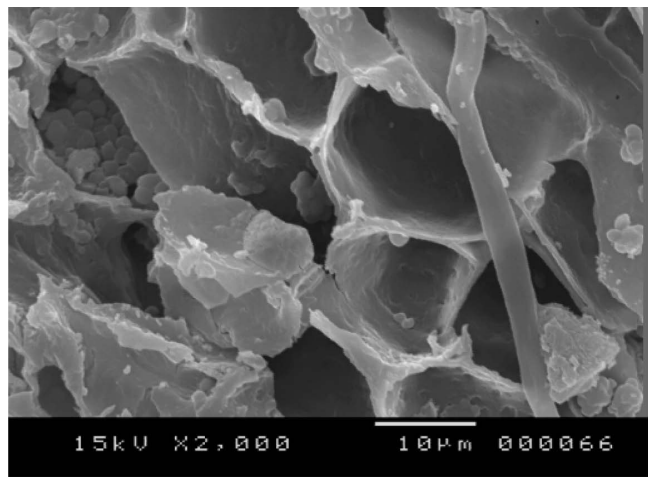

Fig.2 Macrostructures of rice hull.

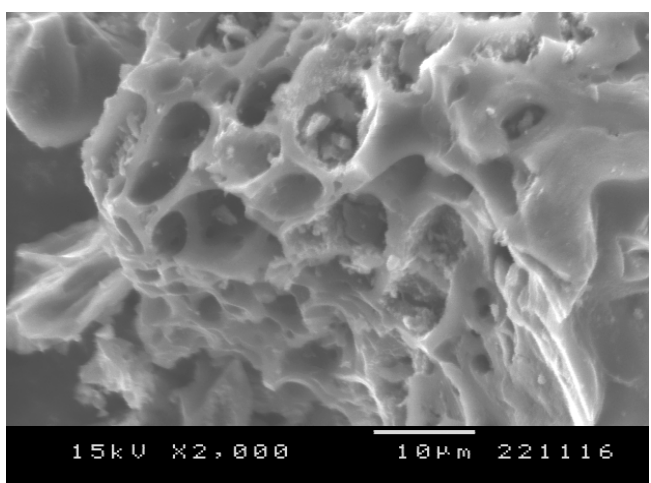

Fig. 3 Macrostructures of RHC powder that was carbo -nized at $900^{\circ} \mathrm{C}$.

Table 1 lists the RHC powder contents of the test pieces. The test piece thickness was $2.5 \mathrm{~mm}$ for the test pieces to evaluate the effect of the RHC powder content. The powder content was 300 per hundred rubber (phr) when the effect of the test piece thickness was evaluated.

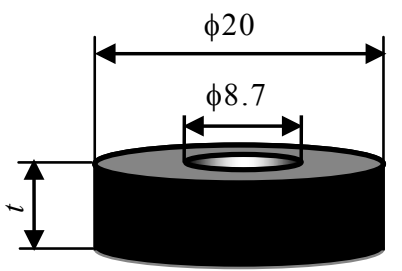

(a) Test piece for $50 \mathrm{MHz}-3 \mathrm{GHz}$.

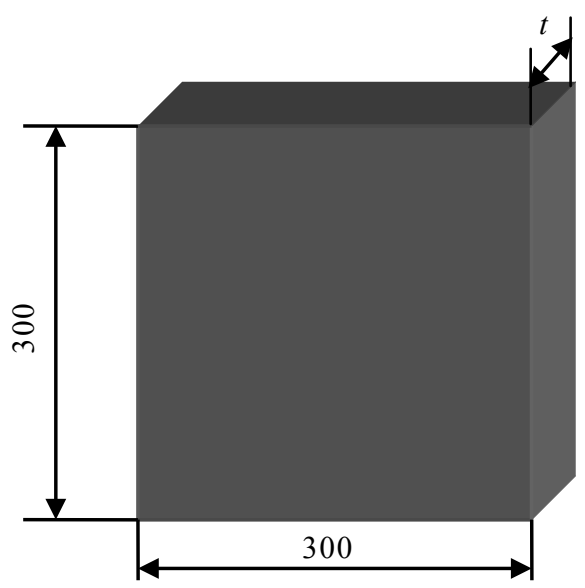

(b) Test piece for $2 \mathrm{GHz}-8 \mathrm{GHz}$.

Fig.4 Geometry of test pieces for electromagnetic wave absorption. (a) is used for S parameter method, (b) is used for arch method.

\subsection{Electromagnetic wave absorption tests}

The electromagnetic wave absorption in the $50 \mathrm{MHz}$ $-3 \mathrm{GHz}$ was measured by the $\mathrm{S}$ parameter method. Fig.5 shows the measuring system of the $\mathrm{S}$ parameter method. The test piece was put into a jig and the measurement, applied the incident wave perpendicularly to the test piece. 
Table 1 Thickness and RHC powder contents of test piece.

\begin{tabular}{|c|c|c|}
\hline No. & Thickness [mm] & Content [phr] \\
\hline 1 & \multirow{3}{*}{2.5} & 100 \\
\cline { 1 - 1 } 2 & & 200 \\
\cline { 1 - 1 } 3 & & 300 \\
\cline { 1 - 1 } 4 & & 400 \\
\hline 5 & 0.5 & \\
6 & 1 & \multirow{2}{*}{} \\
7 & 1.5 & \multirow{2}{*}{300} \\
\hline 8 & 2 & \\
\hline 9 & 2.5 & \\
\hline 10 & 5 & \\
\hline
\end{tabular}

Reflective Wave Incident Wave

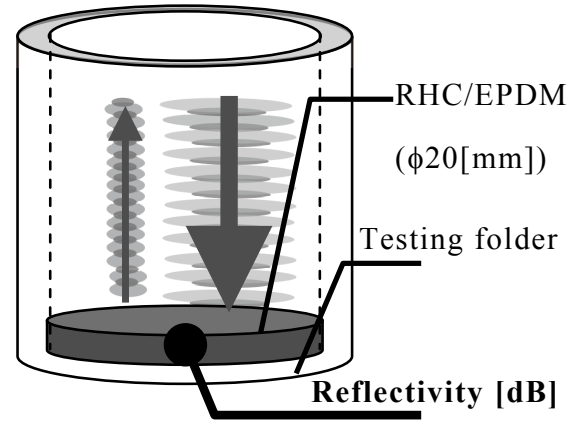

Fig. 5 Measuring system by S parameter method for $50 \mathrm{MHz}-3 \mathrm{GHz}$.

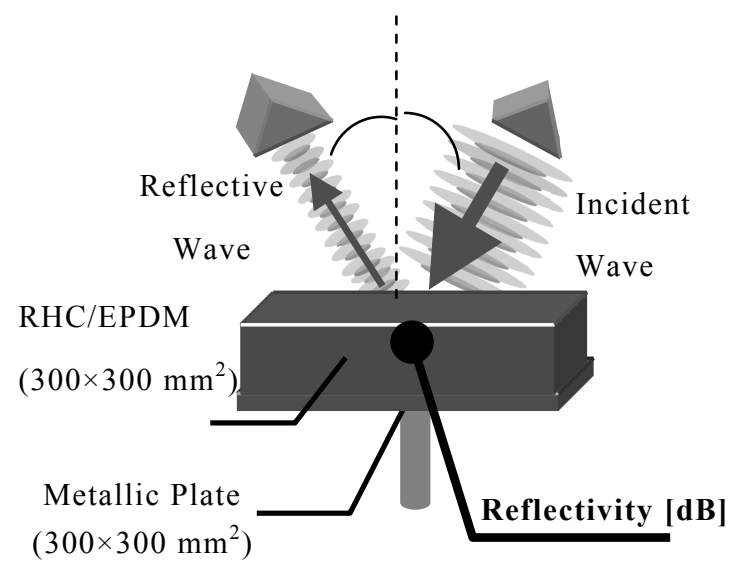

Fig. 6 Measuring system by arch method for $2 \mathrm{GHz}$ $-8 \mathrm{GHz}$.

The electromagnetic wave absorption characteristic under $2 \mathrm{GHz}-8 \mathrm{GHz}$ was evaluated by using the arch testing method. Fig. 6 shows the measuring system of the arch testing method. The incident wave was applied from the transmitter to the test piece. The amount of electromagnetic wave absorption (reflectivity) was evaluated using the power loss between the incident wave and the reflective wave in each frequency.

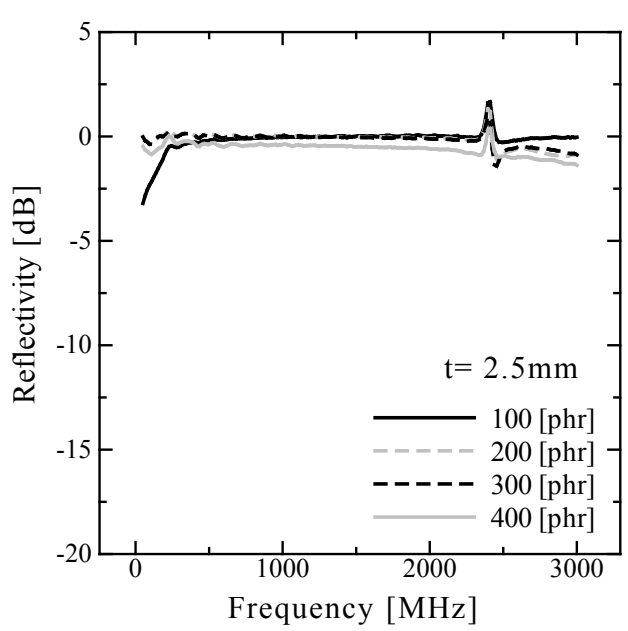

(a) $50 \mathrm{MHz}-3 \mathrm{GHz}$.

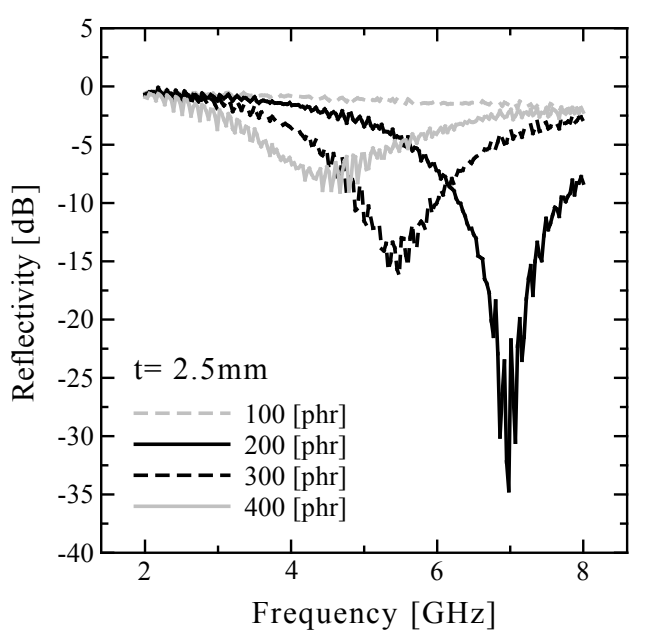

(b) $2 \mathrm{GHz}-8 \mathrm{GHz}$.

Fig.7 Effect of RHC powder content in RHC/EPDM on electromagnetic wave absorption (reflect -ivity).

\section{EXPERIMENTAL RESULTS AND DISCUSSION}

3.1 Effect of powder content on reflectivity

Fig.7 (a) shows the effect of the amount of RHC powder on the characteristic of electromagnetic wave absorption for $50 \mathrm{MHz}-3 \mathrm{GHz}$. The electromagnetic wave absorption was low, and about $-3 \mathrm{~dB}$ or less.

Fig.7 (b) shows the effect of the RHC powder on the characteristic of electromagnetic reflectivity for $2 \mathrm{GHz}-8 \mathrm{GHz}$. The test piece with $200 \mathrm{phr}$ has considerably high electromagnetic wave absorption of about $-35 \mathrm{~dB}$ at about $7 \mathrm{GHz}$. The test piece with $300 \mathrm{ph}$ has about $-15 \mathrm{~dB}$ peak value at about $5.3 \mathrm{GHz}$ absorption frequency.

The distance between the RHC powders is considered to be narrow in the RHC/EPDM in which a lot of RHC powders were included. We have confirmed that the high powder composite of the RHC/EPDM had a 


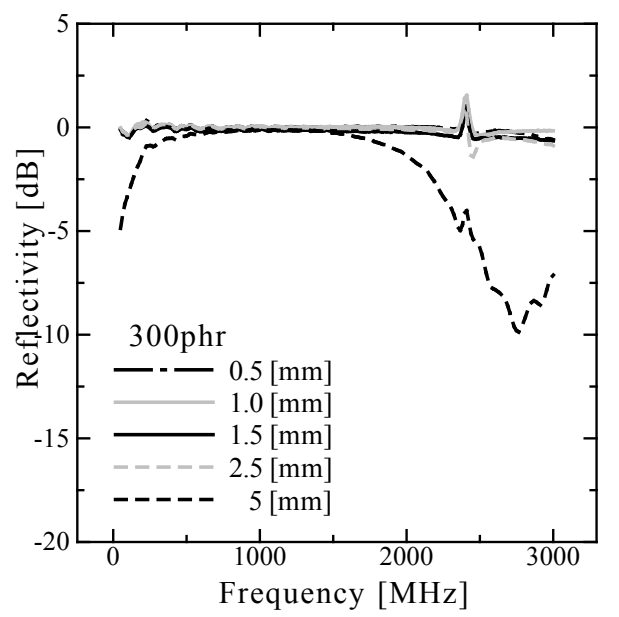

(a) $50 \mathrm{MHz}-3 \mathrm{GHz}$.

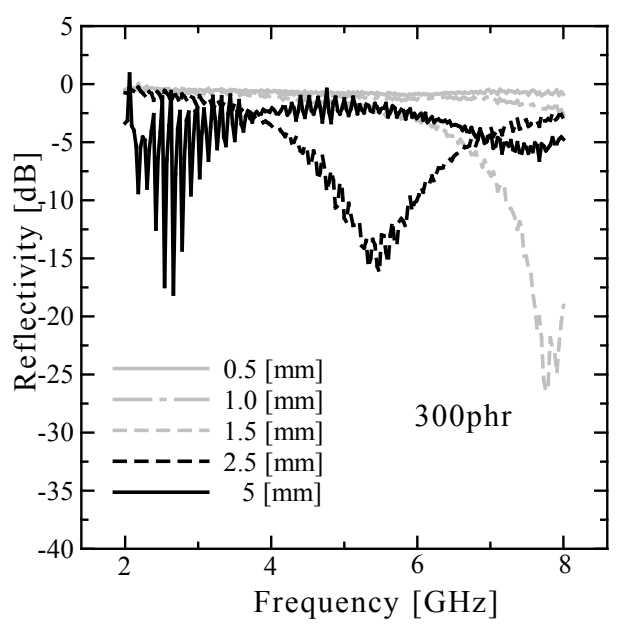

(b) $2 \mathrm{GHz}-8 \mathrm{GHz}$

Fig. 8 Effect of Board thickness on electromagnetic wave absorption (reflectivity).

high electromagnetic wave shielding under low frequency band of $1-1000 \mathrm{MHz}$, although the wave penetrated in the low powder content of RHC/EPDM. The results of Fig.7 (a) implies that the electromagnetic wave is almost reflected on the test piece surface under low frequency bands. Therefore, it is considered that there is a reasonable amount of RHC powder content for the wave absorption.

Moreover, the peak absorption values and the absorption frequency are changed with amount of the filler content as shown in Fig.7 (b).

\subsection{Effect of test piece thickness}

Fig.8 (a) shows the effect of test piece thickness on the reflectivity for $50 \mathrm{MHz}-3 \mathrm{GHz}$. The test piece with thickness $5 \mathrm{~mm}$ has the peak value of about $-5 \mathrm{~dB}$ at about $50 \mathrm{MHz}$, and about $-10 \mathrm{~dB}$ at about $2.7 \mathrm{GHz}$.

Fig. 8 (b) shows the effect of test piece thickness on the reflectivity for $2 \mathrm{GHz}-8 \mathrm{GHz}$. The test piece thickness $1.5 \mathrm{~mm}$ obtained the high electromagnetic wave absorption of about $-25 \mathrm{~dB}$ at about $8 \mathrm{GHz}$. Moreover, the test piece with thickness $2.5 \mathrm{~mm}$ obtained about $-15 \mathrm{~dB}$ at about $5.5 \mathrm{GHz}$, and the test piece with thickness $5 \mathrm{~mm}$ was obtained about $-10 \mathrm{~dB}$ at about $2.6 \mathrm{GHz}$. The peak values and the absorption frequency are changed with the test piece thickness.

These results show that there is an optimum combination of the RHC powder content and the test piece thickness to obtain a high electromagnetic wave absorption for a given frequency band.

\section{CONCLUSION}

The characteristic of electromagnetic wave absorption was measured in frequency band of $50 \mathrm{MHz}-8 \mathrm{GHz}$ for the composite material of RHC/EPDM. The authors evaluated the influence of RHC powder contents and test piece thickness. The summary of the obtained results was described as follows.

(1) The considerably high electromagnetic wave absorption of about $-35 \mathrm{~dB}$ at about $7 \mathrm{GHz}$ was obtained for test piece with $200 \mathrm{phr}$.

(2) The peak values and the absorption frequency are changed with the powder contents and test piece thickness.

(3) There is an optimum combination of the RHC powder contents and the test piece thickness to obtain a high electromagnetic wave absorption for a given frequency band.

\section{ACKNOWLEDGMENTS}

The authors wish to express their gratitude to Associate Professor Hiroki Anzai, Tsuruoka National College of Technology, for his experimental support.

The authors wish to express their gratitude to the Ministry of Agriculture, Forestry and Fisheries of Japan for their financial support on "New technology development for activation of food industry by academic, industry, and governmental cooperation"

\section{REFERENCES}

[1] T.Ishitani, K.Ohtsubo, "The Science of Rice (in Japanese)", Asakura Shoten, Tokyo (1995) p.172.

[2] S.Chandrasekhar, K.G.Styanarayana, P.N.Pramada, P.Raghavan, "Processing Properties and Applications of Reactive Silica from Rice Husk", J. Mater. Sci., 38, 3159-68 (2003).

[3] H.Iizuka, G.Kato, K.Igarashi, S.Shikano and T.Takahashi, "Mechanical Properties of Porous Carbon Materials made from Rice Bran", J. Soc. Mater. Sci. Jpn. 49, 625-630 (2000).

[4] M.Shishido, S.Kubo, T.Takahashi and H.Iizuka, "Mechanical Properties of Porous Carbon Materials made from Rice Hull", Trans. Mater. Res. Soc. Jpn. 31, 993-996 (2006).

[5] M.Shishido, Y.Kurita, M.Ishikawa and H.Iizuka, Trans. Mater. Res. Soc. Jpn. 32, No.4, 1039-1042. (2007).

(Received December 12, 2008;Accepted September 16, 2009) 